JOURNAL OF THEORETICAL

AND APPLIED MECHANICS

54, 2, pp. 551-560, Warsaw 2016

DOI: $10.15632 /$ jtam-pl.54.2.551

\title{
IMPROVING MECHANICAL PROPERTIES OF EPOXY BY ADDING MULTI-WALL CARBON NANOTUBE
}

\author{
Basim M. Fadhil, Payman Sahbah Ahmed \\ Manufacturing Engineering Department, Koya University, Koysinjaq, Irak \\ e-mail: basim.fadhil@koyauniversity.org \\ Ava Ali Kamal \\ Engineering and Projects Directorate, Salahadin University, Erbil, Irak \\ e-mail:avaali@yahoo.com
}

\begin{abstract}
In this research, multi-walled carbon nanotubes (MWCNTs) are used as the reinforcement in an epoxy resin with weight percentages $(0,0.2,0.4,0.6,0.8,1) \mathrm{wt} \%$, respectively, by using both direct (nonhomogeneous) and homogeneous dispersion mixing processes to prepare (epoxy/MWCNTs) nanocomposites. Tensile and drop weight impact tests are used to evaluate mechanical properties of the composites. Results show that homogeneous dispersion has a great effect on enhancing mechanical properties of multi-wall carbon nanotube reinforced composites. Adding $0.2 \mathrm{wt} \%$ of MWCNTs enhances and increases tensile properties, and adding $0.6 \mathrm{wt} \%$ of MWCNTs enhances impact properties.
\end{abstract}

Keywords: multi-wall carbon nanotubes, mechanical properties and nanocomposites

\section{Introduction}

$\mathrm{CNT} /$ polymer composites are increasingly used for engineering applications under hard working conditions due to unique mechanical properties of CNTs, such as high elastic modulus, tensile strength and strain to fracture, ability to withstand cross-sectional and twisting distortions and compression without fracture combined with a low specific weight and high resistance to degradation in order to ensure safety and economic efficiency (Du et al., 2007; Walter et al., 1997).

Epoxy based Multi-Walled Carbon Nanotubes (MWCNTs) reinforced composites are synthesized by Samal (2009) by the method of sonication. The variation of nature of the reinforcement (aligned and randomly oriented MWNTS) has resulted in the improvement of mechanical properties like flexural modulus, tensile strength and hardness. A small change in chemical treatment of the nanotubes has a great effect in the mechanical and morphological properties of the nanocomposites due to the effective load transfer mechanism and state of dispersion. The change in properties has been verified by optical microscopy and scanning electron microscopy. Apart from that the prepared composites have been treated under different temperatures (like hot water, room temperature and liquid nitrogen temperature) and the change in mechanical as well as morphological nature has been verified by SEM of fractographic surface, this proved the elasticity and ductility of the composites.

Multi-walled carbon nanotubes (MWCNTs) were used by Nemaa et al. (2014) to enforce the blend of epoxy/polysulfide and then tensile and wear behavior of this reinforcement were evaluated. For achieving this goal, different weight percentages of MWCNT (0.2-0.6 wt\%) were dispersed in the epoxy resin, then polysulfide resin was added and mixed with two curing 
agents. Experimental results have shown significant difference between epoxy/polysulfide and CNT/epoxy/polysulfide in mechanical properties. With 0.2-0.6\% MWCNTs we observed an increase in Young's modulus from 245 to $273 \mathrm{MPa}$, tensile strength from 30.5 to $38.9 \mathrm{MPa}$ and fracture strain from $12.4 \%$ to $14.2 \%$. For understanding the structure and morphology of nanocomposite, the dispersion states were studied using scanning electron microscopy (SEM) and field emission electron microscopy (FESEM).

Different types of Multi-Walled Carbon Nanotubes (MWCNTs) long and short were used by Al-Rawi et al. (2014) as the reinforcement in an epoxy resin with weight percentages $(0.1,0.2,0.5,1.0,1.5,2.0,2.5,3.0,3.5,4.0,4.5,5) \mathrm{wt} \%$, respectively, by using direct mixing processes to prepar (epoxy/MWCNTs) nanocomposites. The ultrasonic mixing process was used to disperse the nanotubes into the epoxy resin system. The results show improvement of the mechanical properties with an increase in the percentage weight less than $2 \%$ and then a decreament with a further increase in the MWCNTs content. The results show that long carbon nanotubes have mechanical properties better than short carbon nanotubes.

A systemic evaluation was done by $\mathrm{Ci}$ and Bai (2006), for different reinforcement roles of carbon nanotubes in those nanocomposites with different matrix stiffnesses while the curing process were controlled. Both mechanical tests and microscope observations indicated that such a reinforcement would gradually reduce while increasing the stiffness of matrix. However, in soft and ductile composites, carbon nanotubes show a significant reinforcement without fracture strain growth. The interface interaction is poor between carbon nanotubes and matrix in the stiff composite, and therefore, they have little contribution to the mechanical properties of the composite.

In this research, Multi-Walled Carbon Nanotubes (MWCNTs) are used as the reinforcement in an epoxy resin with weight percentages $(0,0.2,0.4,0.6,0.8,1) \mathrm{wt} \%$, respectively, by using direct and homogeneous dispersion mixing processes to prepare (epoxy/MWCNTs) nanocomposites. Tensile and drop weight impact tests are used to evaluate the mechanical properties of the composites.

\section{Experimental part}

Epoxy resin of a trade mark (Quickmast 105 base) is used as the matrix which is a liquid of low viscosity as compared with other thermosets, and it is converted to solid state by adding a hardener (Quickmast 105 hardener) at ratio of 3:1, the technical properties of Quickmast 105 according to the data sheet of DCP company are listed in Table 1; while the nanoparticle reinforcements are MWCNTs manufactured by Henan Huier Nano Technology Co. Ltd. Their technical properties are listed in Table 2.

Table 1. Technical properties of Quickmast 105 (provided by the supplier)

\begin{tabular}{|c|c|c|c|c|c|}
\hline $\begin{array}{c}\text { Compressive } \\
\text { strength } \\
\text { BS6319 }\end{array}$ & $\begin{array}{c}\text { Flexural } \\
\text { strength } \\
\text { BS6319 }\end{array}$ & $\begin{array}{c}\text { Tensile } \\
\text { strength } \\
\text { BS6319 }\end{array}$ & Pot life & $\begin{array}{c}\text { Specific } \\
\text { gravity }\end{array}$ & Viscosity \\
\hline \hline$>72 \mathrm{MPa}$ & $>50 \mathrm{MPa}$ & $>20 \mathrm{MPa}$ & $60 \mathrm{~min}$ & 1.1 & $\begin{array}{c}3-5 \text { poise } \\
25^{\circ} \mathrm{C}\end{array}$ \\
\cline { 4 - 6 } & $25^{\circ} \mathrm{C}$ & & $25^{\circ} \mathrm{C}$ & & $\begin{array}{c}1-2 \text { poise } \\
35^{\circ} \mathrm{C}\end{array}$ \\
& & & & & \\
\end{tabular}

To prepare a carbon nanotubes/epoxy composite, the nanotube powder (with a content of $0,0.2,0.4,0.6,0.8$, and $1 \mathrm{wt} \%$ ) was added into the liquid epoxy in two ways: 
Table 2. Technical properties of multi-wall carbon nanotube (provided by the supplier)

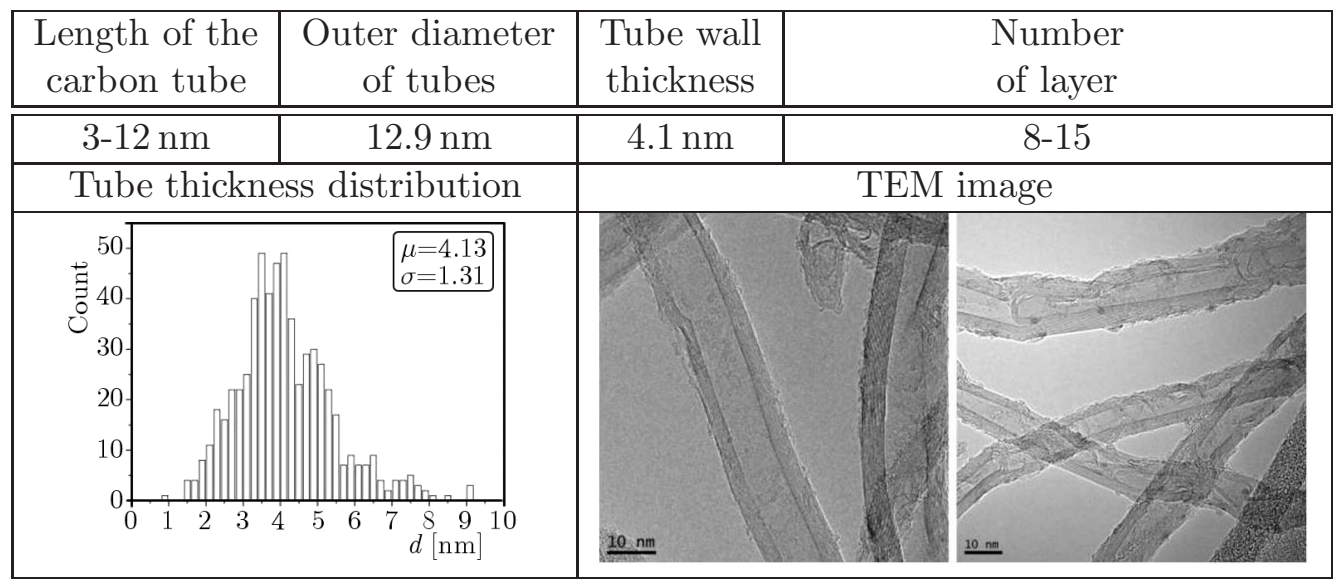

1. Nonhomogeneous dispersion: the resin and carbon nanotube solution was manually stirred for $5 \mathrm{~min}$ to form a homogeneous suspension. And then an epoxy hardener was mixed into the carbon nanotubes/epoxy suspension, and softly stirred for about 2 min. Finally, the composite suspension was poured into the impact and dog-bone-like steel tensile mould and left to be cured at room temperature for 7 days.

2. Homogeneous dispersion: the resin and carbon nanotube solution was manually stirred for 10 min to form a homogeneous suspension. And then an epoxy hardener was mixed into the carbon nanotubes/epoxy suspension, softly stirred for about $10 \mathrm{~min}$, and the mixture was left for $2 \mathrm{hrs}$ to get homogeneous dispersion. Finally, the composite suspension was poured one corner into the impact and dog-bone-like steel tensile mould (to avoid bubble formation which causes cast damage) and left to be cured at room temperature for 7 days.

Samples without carbon nanotube addition (matrix samples) were also fabricated for comparison.

Mechanical tests were done according to ASTM D638 [3] for a tensile test and ISO 6603 [10] for an impact test. Instron 5982 tensile test machine was used to measure tensile behavior of the samples at strain rate of $2 \mathrm{~mm} / \mathrm{s}$. The specimen was fixed straightly by using two jaws with $100 \mathrm{kN}$ maximum load. The machine started to elongate the specimen at a constant rate, and to continuously and simultaneously measure the instantaneous applied load and the resulting extension. Instron Ceast 9350 instrumented with the Drop weight impact tester was used to measure the resistance to failure of a material subjected to a suddenly falling object (weight $=5.8 \mathrm{~kg}$ ) from a level of $700 \mathrm{~mm}$. The machine started to continuously and simultaneously measure the instantaneous impact load and the resulting deformation and impact energy (absorbed energy).

\section{Results and discussion}

During the study, multi-walled carbon nanotubes (MWCNTs) were used as the reinforcement in the epoxy resin with weight percentages $(0,0.2,0.4,0.6,0.8,1) \mathrm{wt} \%$, respectively, by using direct and homogeneous dispersion mixing processes to prepare (epoxy/MWCNTs) nanocomposites. Tensile and drop weight impact test were carried out used to evaluate the mechanical properties of the composites. The relationships of stress-strain, impact force-time, impact forcedeformation, impact energy-time and impact energy-deformation were obtained from experimental data as follows. 


\subsection{Tensile test results}

Figure 1 shows the stress-strain results of the composites used in this study with different multi-walled carbon nanotubes (MWCNTs) reinforcement in the epoxy: 0, 0.2, 0.4, 0.6, 0.8, and $1 \mathrm{wt} \%$ for two mixing techniques, i.e. nonhomogeneous and homogeneous dispersion.
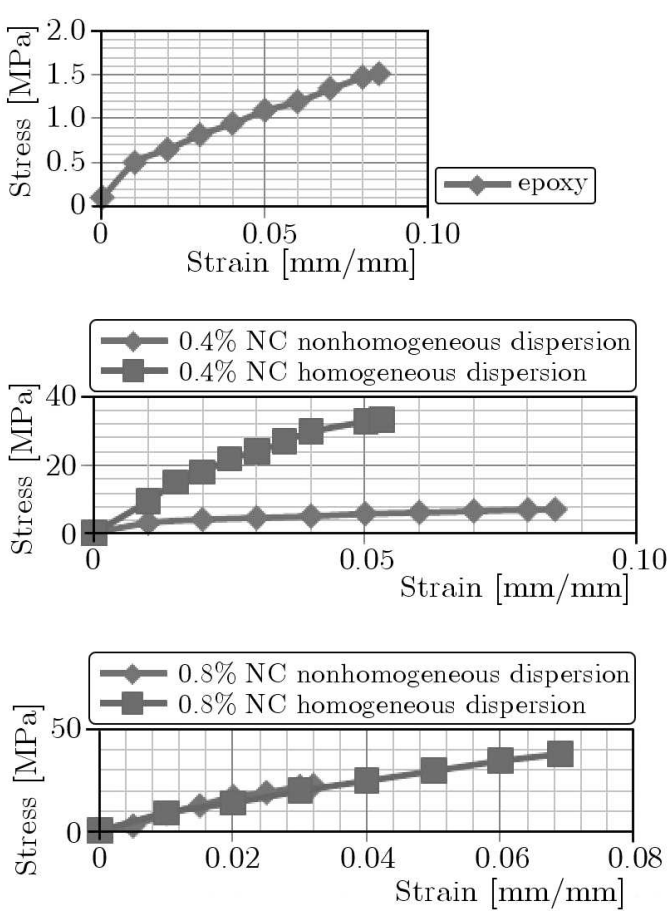
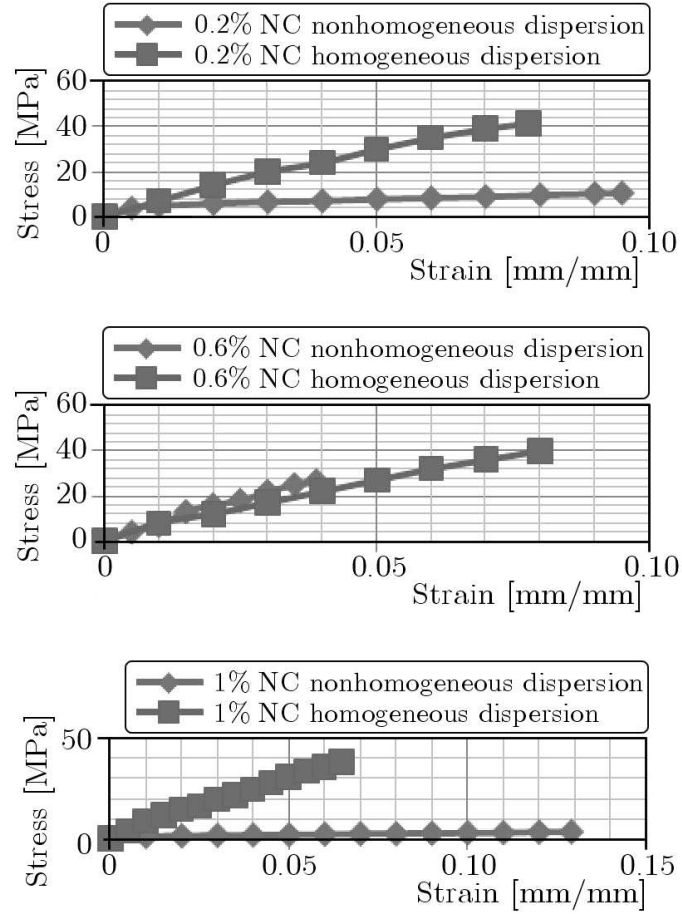

Fig. 1. Stress-strain curves of the composites with different percentages of multi-wall carbon nanotube: $0,0.2,0.4,0.6,0.8$, and $1 \mathrm{wt} \%$
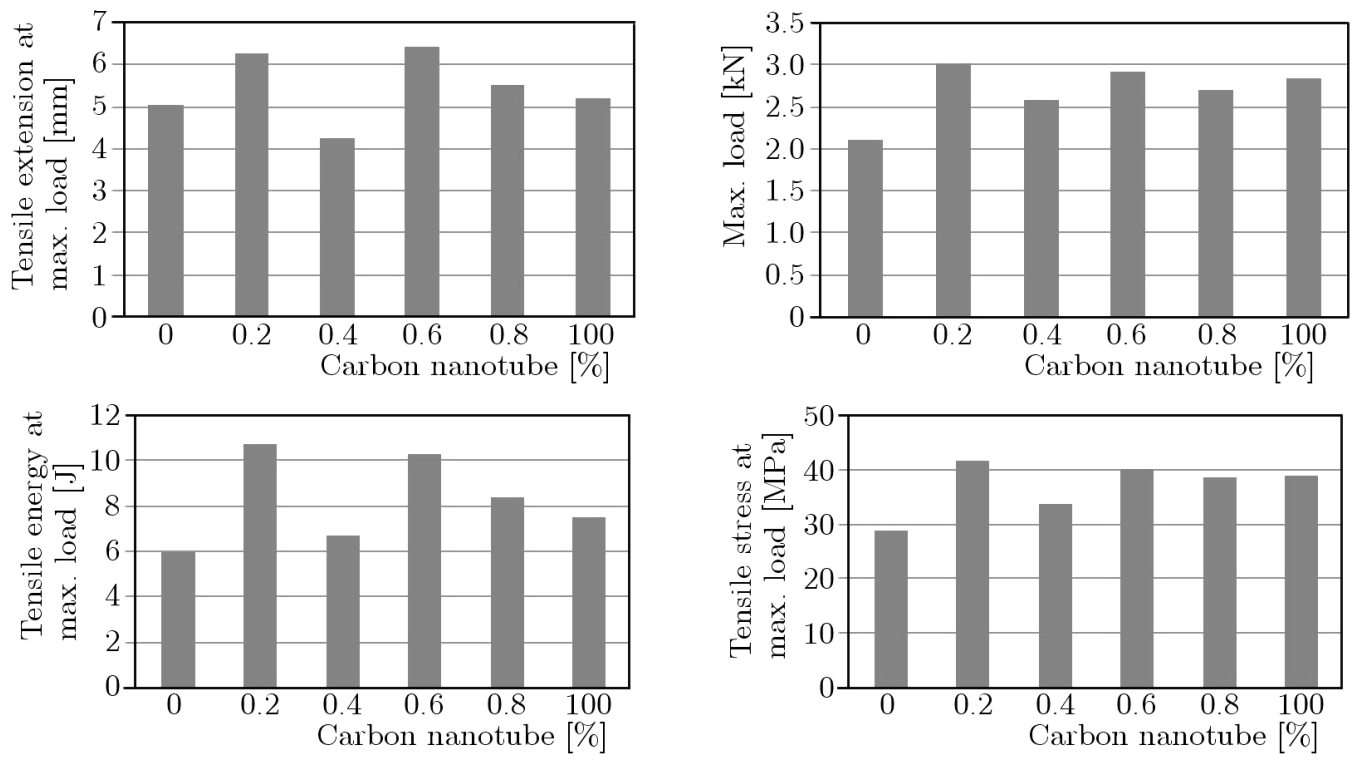

Fig. 2. Tensile stress, extension and energy at maximum load in the composites with different percentages of MWCNTs reinforcement in the epoxy: $0,0.2,0.4,0.6,0.8$, and $1 \mathrm{wt} \%$

It can be seen that the dispersion has a great effect on the stress and strain values for all composites. Such low reinforcing ability of the nanotubes in epoxy nanocomposites, which is sometimes observed, can be explained by a number of reasons: one is lack of interfacial adhesion, 
which is critical for load transfer in composites. Indeed, carbon nanotube surfaces are atomically smooth, which may limit the transfer of load from the matrix to nanotubes reinforcement (Cooper et al., 2000; Bokobza, 2007). Another reason is poor dispersion of nanotubes in the polymer matrix, which is also significant for fabrication of reinforced nanocomposites (Gojny et al., 2004). Due to their high aspect ratio and huge surface area, CNTs have strong tendency to agglomerate, which leads to inhomogeneous dispersion in the polymer matrix (Smutisikha, 2010).

Figure 2 shows tensile properties and results of the composites used with different percentages of Multi-Walled Carbon Nanotubes (MWCNTs) reinforcement in the epoxy: 0, 0.2, 0.4, 0.6, 0.8, and $1 \mathrm{wt} \%$.

It can be seen that the content of MWCNTs $(0.2-1 \mathrm{wt} \%)$ enhances and increases the tensile properties and reaches the maximum values for $0.2 \% \mathrm{NT}$ composite: tensile stress at maximum load from 28.6 MPa for epoxy resin to $41.4 \mathrm{MPa}$, maximum load from $2.1 \mathrm{kN}$ for epoxy resin to $2.9 \mathrm{kN}$, tensile extension at maximum load from $5.04 \mathrm{~mm}$ for epoxy resin to $4.2 \mathrm{~mm}$ and tensile energy at maximum load from $5.9 \mathrm{~J}$ for epoxy resin to $10.6 \mathrm{~J}$. Creating attractive polar forces, and Van der-Waals bonding between chains and nanotubes leads to an increase in the constraint between tubes/epoxy chains and epoxy chains, complicates epoxy chains which approach one another, reduces free volume space. This effect of MWCNTs make the epoxy chains bear extra loading (Park et al., 2004). A 0.4\% wt of MWCNTs is better than that of epoxy, but lower than other percentages due to formation of agglomerates of nanotubes in the polymer matrix that reduce the reinforcing effects of the CNTs.

\subsection{Impact test results}

\subsubsection{Impact force - time behavior}

Figure 3 shows time histories of the impact force in the composites used with different percentages of MWCNTs reinforcement in the epoxy: 0, 0.2, 0.4, 0.6, 0.8, and $1 \mathrm{wt} \%$ for two mixing techniques, i.e. nonhomogeneous and homogeneous dispersion.

It can be seen that dispersion has a great effect on the force values for all composites which is attributed to good dispersions of the nanotubes in the matrix and good reactions between the epoxy and grafted nanotubes. The investigation of the fracture surface in nanocomposites revealed that narrower crack-tips underneath the advancing cracks were more efficiently bridged by the nanotubes in epoxy/MWCNTs resulting in an increased resistance against crack propagation (Ajayan et al., 2006).

\subsubsection{Impact force - deformation behavior}

Figure 4 shows the impact force vs. deformation results of composites with different percentages of MWCNTs reinforcement in the epoxy: $0,0.2,0.4,0.6,0.8$, and $1 \mathrm{wt} \%$ for two mixing techniques. It can be seen that dispersion has a great effect on the force values for all composites which is attributed to the formation of a network structure which can take more mechanical loading from the matrix when the matrix is under stress. This means that when the applied loading is over the elastic deformation stress, the carbon nanotubes transfer the stress (Qi etal, 2006), which enhances the strength of the resin matrix.

\subsubsection{Impact energy - time behavior}

Figure 5 shows the impact energy vs. time of composites with different percentages of MWCNTs reinforcement in the epoxy: $0,0.2,0.4,0.6,0.8$, and $1 \mathrm{wt} \%$ for two mixing techniques. It can be seen that dispersion has a great effect on the force values for all composites which is attributed to the weak van der Waals bonding between the reinforcement and the matrix, which 

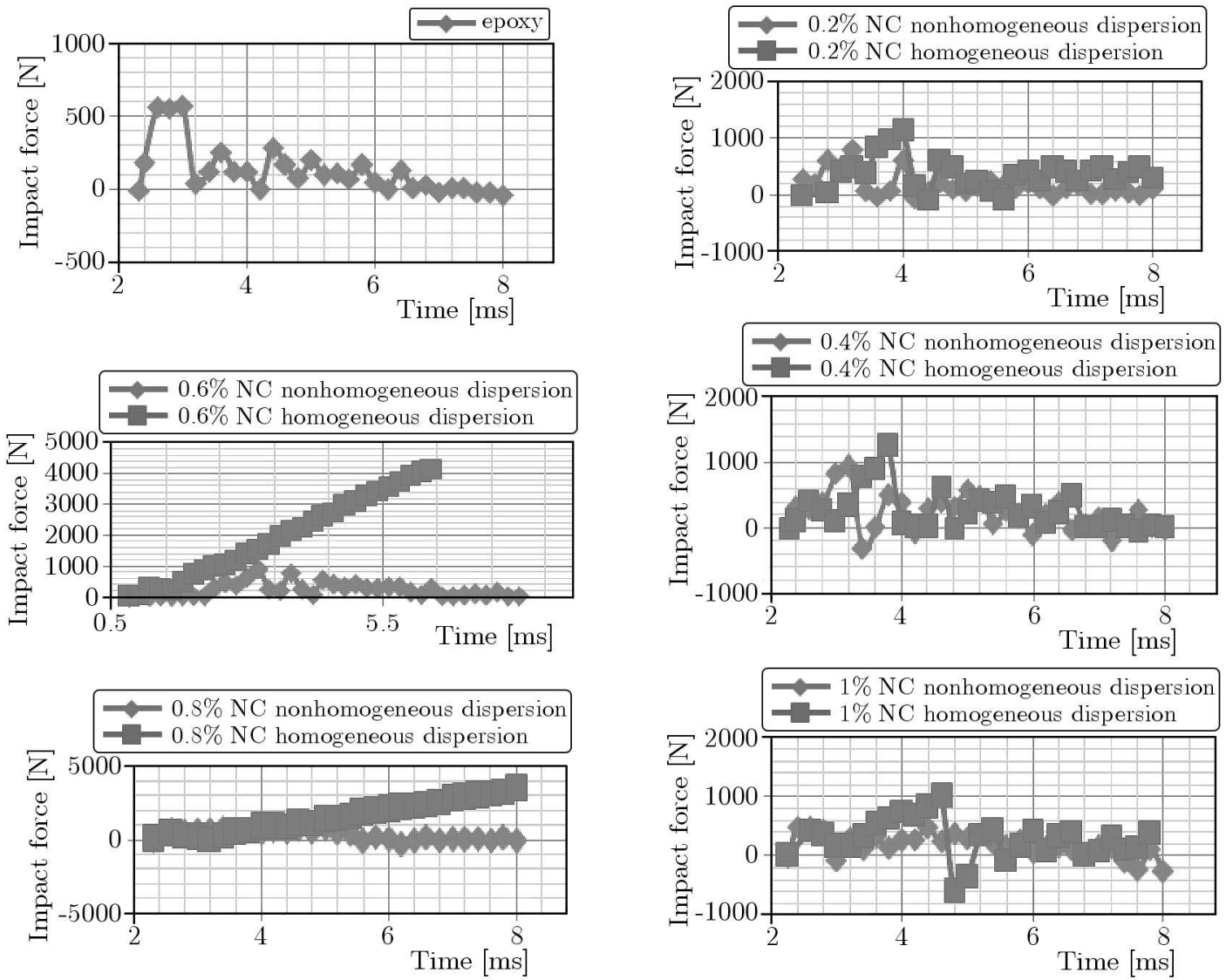

Fig. 3. Impact force vs. time in composites used with different percentages of MWCNTs reinforcement in the epoxy: $0,0.2,0.4,0.6,0.8$, and $1 \mathrm{wt} \%$
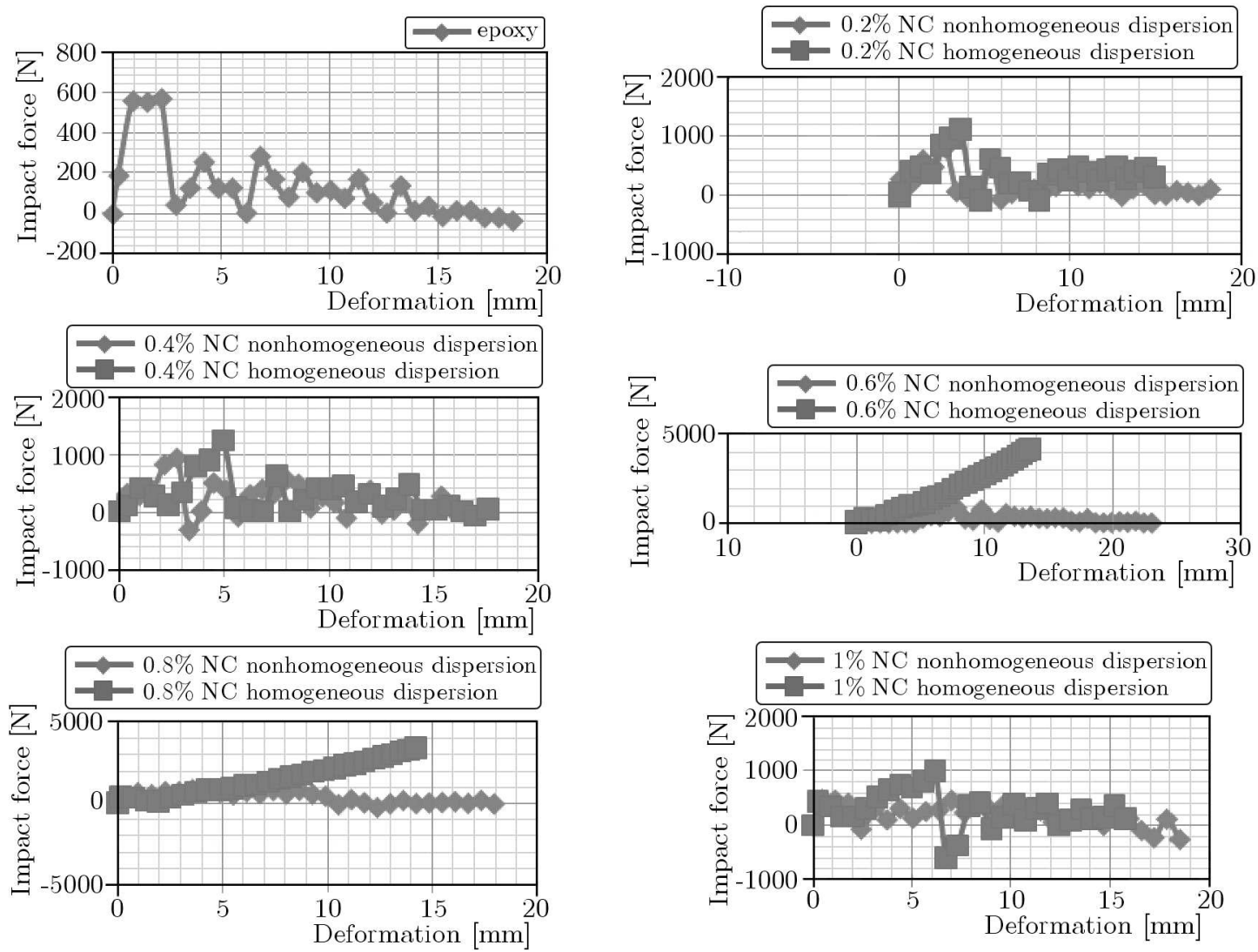

Fig. 4. Impact force vs. deformation of composites with different percentages of MWCNTs reinforcement in the epoxy: $0,0.2,0.4,0.6,0.8$, and $1 \mathrm{wt} \%$ 
is the main load transfer mechanism for $\mathrm{CNT} /$ polymer composites where the interfacial energies normally amount to $\sim 50-350 \mathrm{~mJ} / \mathrm{m}$ (Nardin and Schultz, 1993).
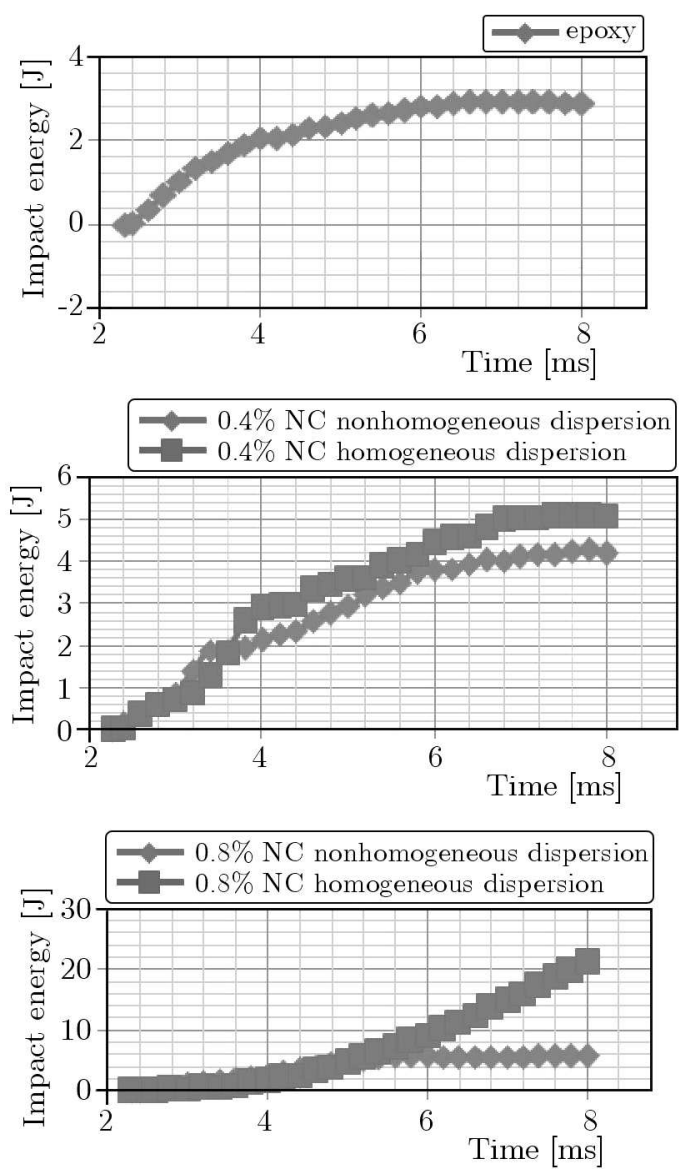
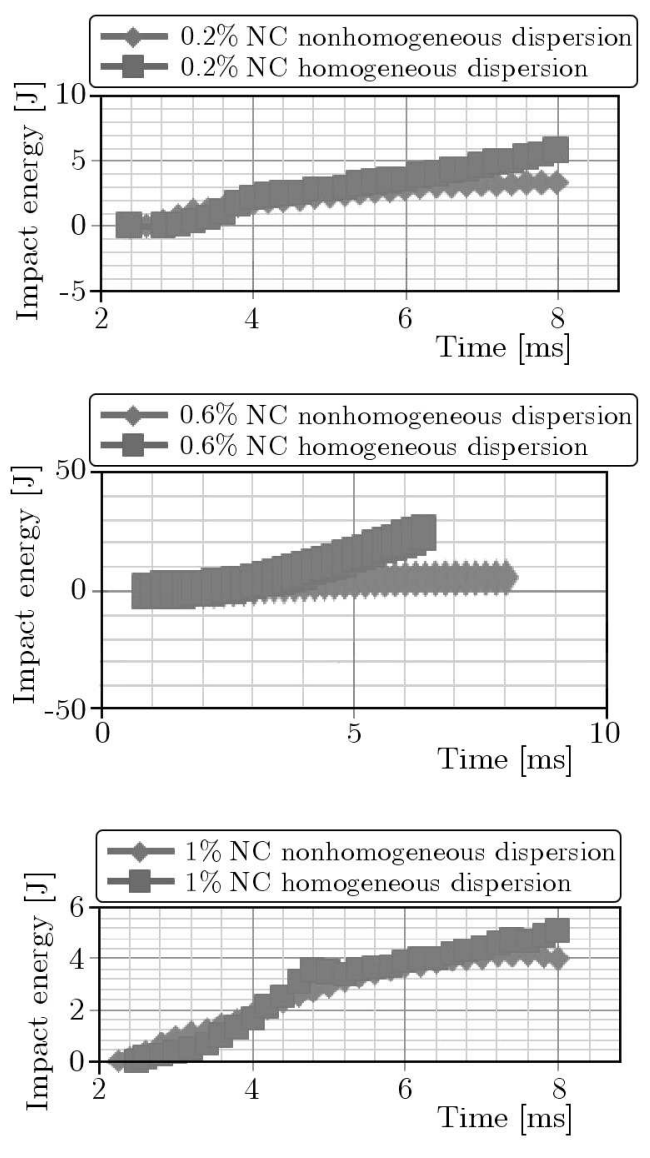

Fig. 5. Impact energy vs. time of composites with different percentages of MWCNTs reinforcement in the epoxy: $0,0.2,0.4,0.6,0.8$, and $1 \mathrm{wt} \%$ fot two mixing techniques

\subsubsection{Impact energy - deformation behavior}

Figure 6 shows the impact energy vs. deformation of composites with different percentages of MWCNTs reinforcement in the epoxy: $0,0.2,0.4,0.6,0.8$, and $1 \mathrm{wt} \%$ for two mixing techniques. It can be seen that dispersion has a great effect on the force values for all composites which is attributed to the micromechanical interlocking, which can be marginal in CNT/polymer composites if CNTs have atomically smooth surface. The van der Waals bonding is increased by using small size reinforcement and close contact at the interface. CNTs are strong enough and inter-connected or long enough to block the movement of polymer chains (Du et al., 2007; Lu, 1997; Meguid and Sun, 2004).

\subsubsection{Effect of multi-wall carbon nanotube percentages on impact properties of the composites}

Figure 7 shows a summary of the effect of adding multi-wall carbon nanotube percentages on impact properties: energy, force and deformation of the composites in this study. It can be seen that both energy and force values are increased up to $0.6 \%$ multi-wall carbon nanotube then they decrease, which is due to critical CNT content in the matrix. This can be found when the CNT strengthening effect on randomly oriented $\mathrm{CNT} /$ polymer composites are investigated. Below this content, the strengthening effect for randomly oriented CNT/polymer composites increases with 

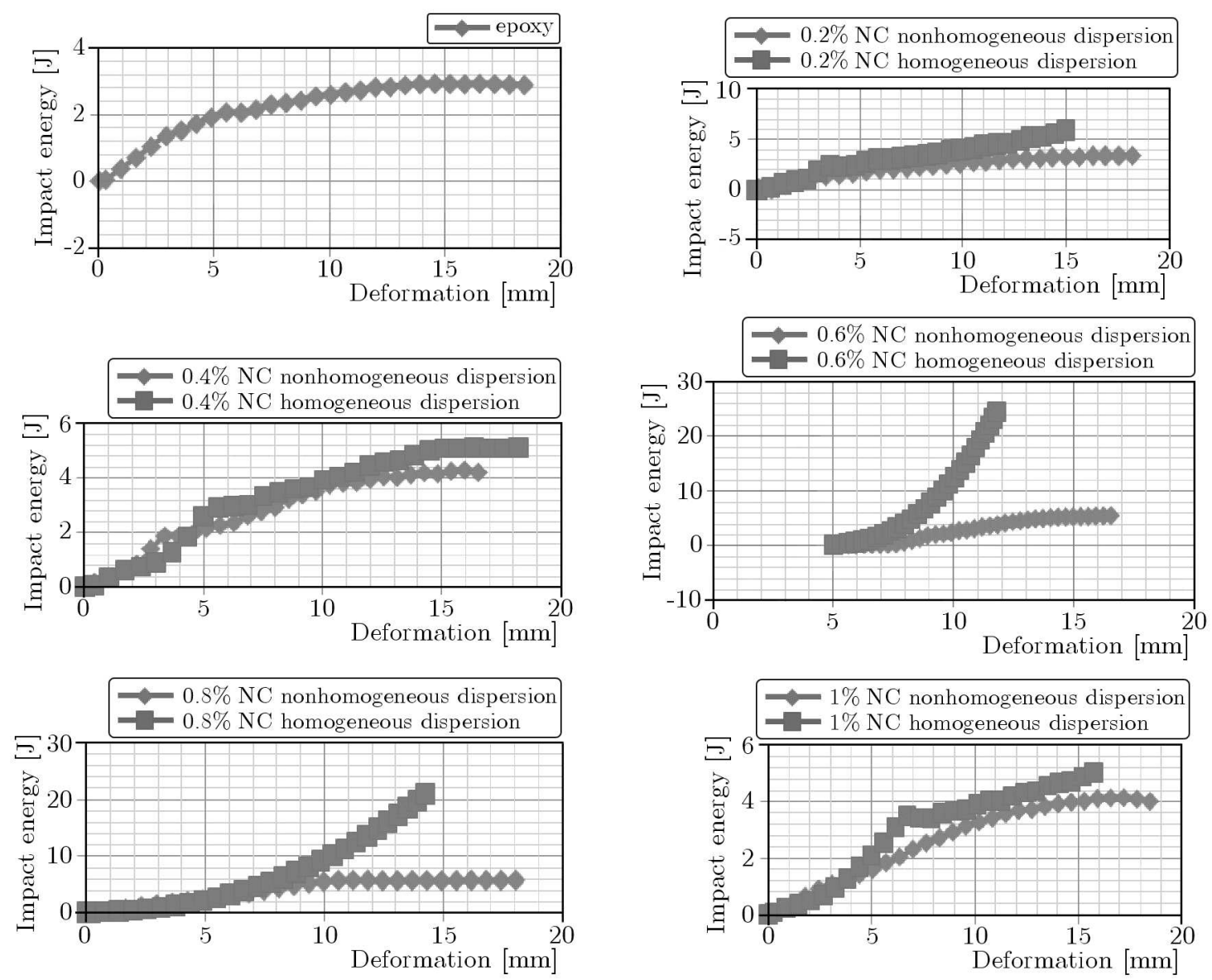

Fig. 6. Impact energy vs. deformation of composites with different percentages of MWCNTs reinforcement in the epoxy: $0,0.2,0.4,0.6,0.8$, and $1 \mathrm{wt} \%$ for two mixing techniques
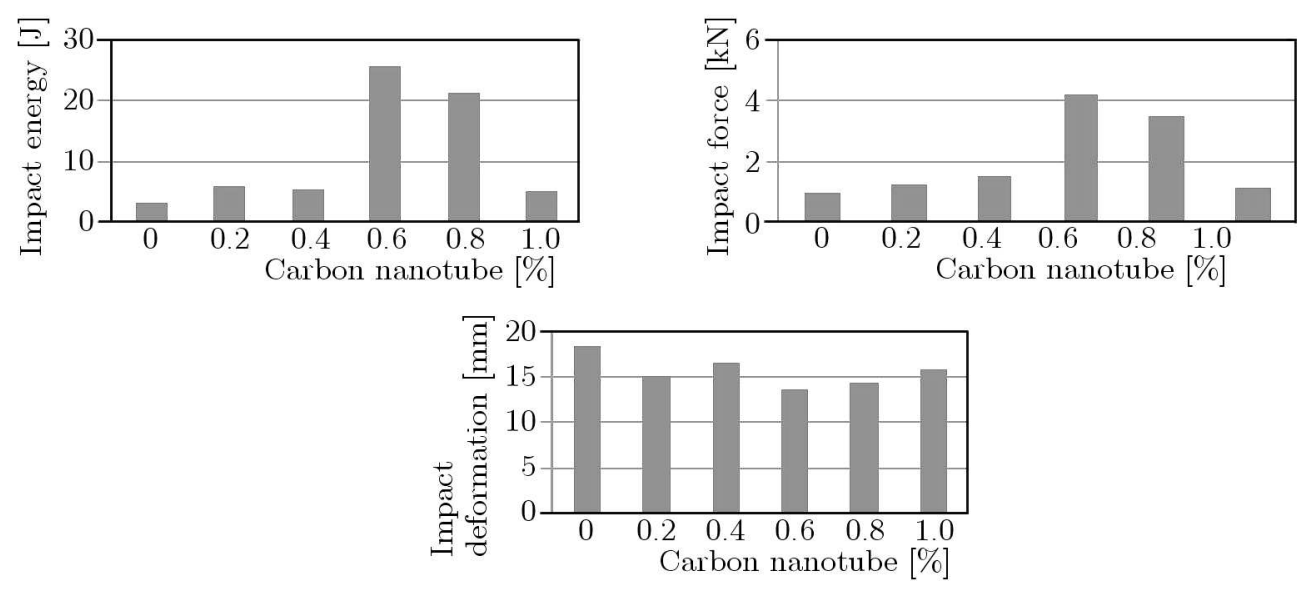

Fig. 7. Effect of adding multi-wall carbon nanotube percentages on impact properties: energy, force and deformation of the studied composites

growing CNT content. Above this content, the strength of CNT/polymer composites decreases. The work of Bai (2003) shows that the critical CNT loading percentage is about $0.5 \mathrm{wt} \%$ for CNT/epoxy composites. The same tendency was reported by Meguid and Sun (2004) in their work on the tensile and shear strength of nano-reinforced composite interfaces. The excess of CNTs increases the viscosity of polymers and can also cause some surface of the CNTs not be completely covered by the polymer matrix due to the large specific surface area of the CNTs. This makes uniform dispersion and load transfer more difficult. Moreover, it is very difficult 
for high quantity of polymers to intercalate among CNTs when the CNT content becomes high (Du et al., 2007). Impact energy and force increases from $2.9 \mathrm{~J}$ and $0.92 \mathrm{kN}$ for the epoxy to its maximum value $25.5 \mathrm{~J}$ and $4.16 \mathrm{kN}$ in $0.6 \% \mathrm{NT}$ composites, and the impact deformation decreases from $18.4 \mathrm{~mm}$ for the epoxy to its minimum value $13.6 \mathrm{~mm}$ in $0.6 \% \mathrm{NT}$ composites.

\section{Conclusions}

- Homogeneous dispersion has a great effect on enhancing mechanical properties of multi-wall carbon nanotube reinforced composites.

- Adding $0.2 \mathrm{wt} \%$ of MWCNTs enhances and increases tensile properties to reach their maximum values as follows: tensile stress at maximum load from 28.6 MPa for epoxy resin to $41.4 \mathrm{MPa}$, maximum load from $2.1 \mathrm{kN}$ for epoxy resin to $2.9 \mathrm{kN}$, tensile extension at maximum load from $5.04 \mathrm{~mm}$ for epoxy resin to $4.2 \mathrm{~mm}$ and tensile energy at maximum load from $5.9 \mathrm{~J}$ for epoxy resin to $10.6 \mathrm{~J}$.

- The impact energy and force increase from $2.9 \mathrm{~J}$ and $0.92 \mathrm{kN}$ for the epoxy to their maximum values of $25.5 \mathrm{~J}$ and $4.16 \mathrm{kN}$, respectively, in $0.6 \% \mathrm{NT}$ composites. The impact deformation decreases from $18.4 \mathrm{~mm}$ for the epoxy to its minimum value $13.6 \mathrm{~mm}$ in $0.6 \%$ NT composites.

\section{References}

1. Al-Rawi K.R, Hedar A.J., and OlfatA.Mahmood O.A., 2014, Effect different multi-walled carbon nanotubes MWCNTs type on mechanical properties of epoxy resin nanocomposites, International Journal of Application or Innovation in Engineering and Management (IJAIEM), 3, 8, ISSN 2319-4847

2. Ajayan P.M., Suhr J., KoratKar N., 2006, Utilizing interfaces in carbon nanotube reinforced polymer composites for structural damping, Journal of Materials Science, 41, 23, 7824-7829

3. Annual Book of ASTM Standard, vol.08.01, 1989

4. BAI J.B., 2003, Evidence of the reinforcement role of CVD multi-walled carbon nanotubes in a polymer matrix, Carbon, 41, 1331-1334

5. Bokobza L., 2007, Mechanical properties and interfacial characteristics of carbon nanotube reinforced epoxy, Journal of Applied Polymer Science, 48, 15, 4907

6. Ci L., BAI J.-B., 2006, The reinforcement role of carbon nanotubes in epoxy composites with different matrix stiffness, Composites Science and Technology, 66, 599-603

7. Cooper C.A., Young R.J., Halsall M., 2000, Mechanical properties of carbon nanotube, Composites Part A: Applied Science and Manufacturing, 32, 5, 401

8. Du J.-H., BAI J., Cheng H.-M., 2007, The present status and key problems of carbon nanotube - based polymer composites, Express Polymer Letters, 1, 5, 253-273

9. Gojny F.H., Wichmann M.H.G., Köpke U., Fiedler B., Schulte K., 2004 Carbon nanotube-reinforced epoxy-composites: enhanced stiffness and fracture toughness at low nanotube content, Composites Science and Technology, 64, 2363-2371

10. ISO 6603-2:2000: International Standard, Plastics - Determination of puncture impact behaviour of rigid plastics - Part 2: Instrumented impact testing Second edition 2000-10-01

11. Lu J.P., 1997, Elastic properties of carbon nanotubes and nanoropes, Physical Review Letters, $\mathbf{7 9}$, 1297-1300

12. Meguid S.A., Sun Y., 2004, On the tensile and shear strength of nano-reinforced composite interfaces, Materials and Design, 25, 289-296 
13. Nardin M., Schultz J., 1993, Effect of elastic-moduli and interfacial adhesion energy on the critical fiber aspect ratio in single-fiber composites, Journal of Materials Science Letters, 12, 1245-1247

14. NemaA A., Al-Razaq I.A., Kader E.E., 2014, Characteristics and properties of epoxy/polysulfide composite materials reinforced by carbon nanotubes, Diyala Journal of Engineering Sciences, 7, 3, 106-119, ISSN 1999-8716

15. PARK S.J., Jeong H.J., NAh C., 2004, A study of oxyfluorination of multi-walled carbon nanotubes on mechanical interfacial properties of epoxy matrix nanocomposites, Materials Science and Engineering A, 385, 13-16

16. Qi H.J., Joyce K., Boyce M.C., 2006, Durometer hardness and the stress-strain behavior of elastomeric materials, Rubber Chemistry and Technology, 76, 2, 419-435

17. Samal S.S., 2009, Role of temperature and carbon nanotube reinforcement on epoxy based nanocomposites, Journal of Minerals and Materials Characterization and Engineering, 8, 1, 25-36

18. Smutisikha B., 2010, Dispersion and reinforcing mechanism of carbon nanotubes in epoxy nanocomposites, Bulletin of Materials Science, 33, 1, 27-31

19. Walter R., Friedrich K., Privalko V., Savadori A., 1997, On modulus and fracture toughness of rigid particulate filled high density polyethylene, The Journal of Adhesion, $\mathbf{6 4}$

Manuscript received July 20, 2015; accepted for print September 22, 2015 